\title{
مقدمة
}

تزايد الاهتمام فى العقد الأخير من القرن العشرين بفاعلية دور وسائل

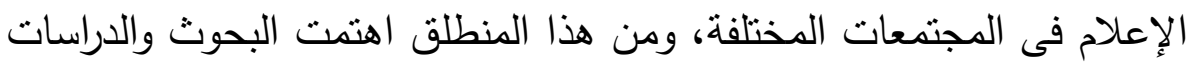

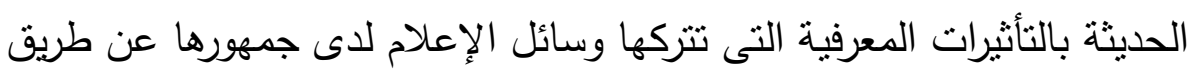

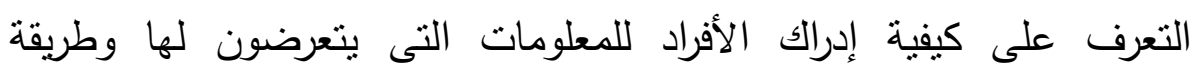

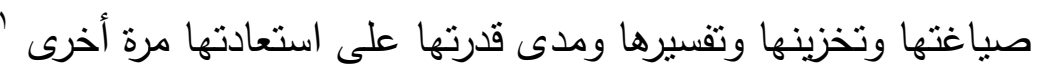

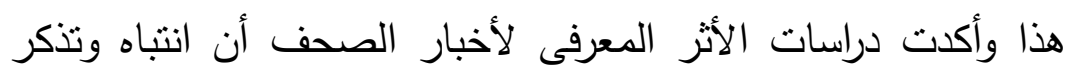

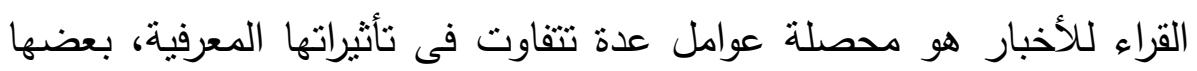
يتعلق بالمحتوى الخبرى وبعضها يتعلق بالصحيفة كوسيلة معلومات واتصال

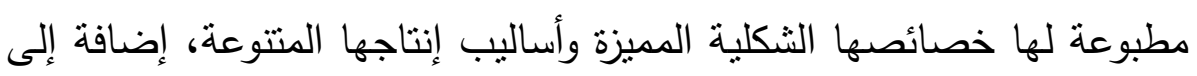

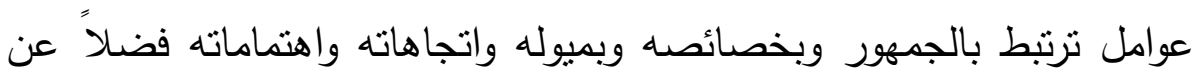

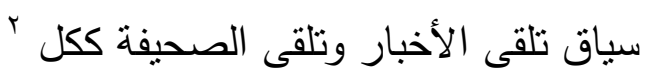
هذا وقد اعتدت الكثير من دراسات الأثر المعرفى على نظرية تمثيل

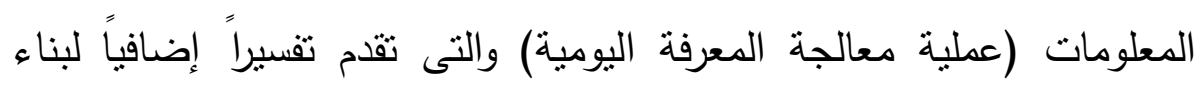

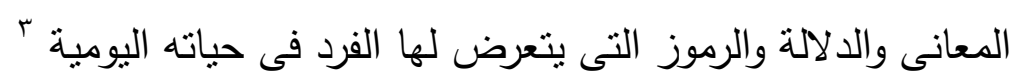

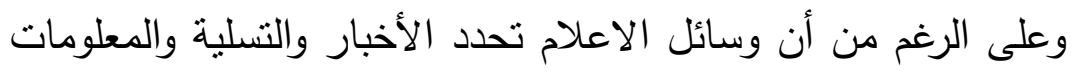
التي يتلقاها الجمهور فإن الناس يستوعبون جزءا من المعلومات التي يستقبلونها

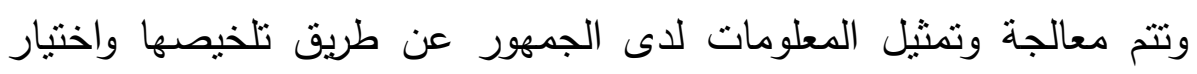

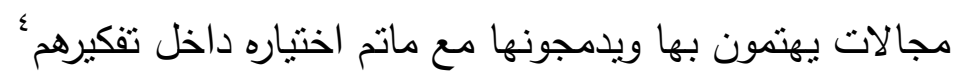

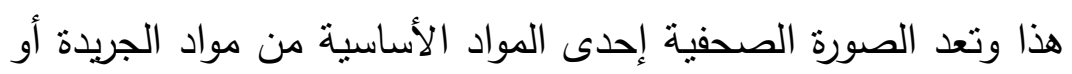

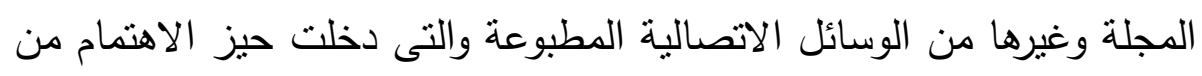




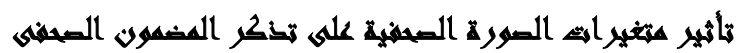

حيث الدراسات التى تتاولت عمليتى الفهم والتذكر لأخبار الصحف والمعلومات التى تتضمنها هذه الأخبار .

ومن هذا المنطلق تسعى هذه الدراسة إلى معرفة تأثيرمتغيرات الصورة

الصحفية على عمليتى جذب انتباه وتذكر القراء للمضمون المقدم من الصحيفة - دراسة هشام محمود مصباح (7 99 ام) "فهم وتذكر الأخبار فى التليفزبون المصرى فى إطار نظرية تمثيل المعلومات.

استخدمت هذه الدراسة المنهج التجريبى للتطبيق على عينة من طلبة

الجامعة بهدف التعرف على تأثثر بعض عوامل إنتاج أو تقديم الخبر التليفزيونى على عمليات التمثيل التى يقوم بها الجهاز المعرفى للفرد، وهو ما تظهر انعكاساته فى تذكر المشاهد ومدى فهمه للمعلومات التى يقدمها الخبر • وتوصلت الدراسة الى ارتفاع متوسط تذكر الخبر عندما يأتى فى بداية النشرة مقارنة بمنوسط تذكره عندما يأنى فى وسط النشرة. وكثفت الدراسة عن تأثير بعض عوامل الإنتاج على مستويات الفهم والتذكر.

1997 Mendelson, Andrew Lawrence دراسة أندرو لاورنس تأثثيرات الإبداع في الصور الإخبارية على الانتباه والتذكر. هدف هذه الدراسة هو تأثثير الإبداع في محتوى وتنكوين الصورة الإنداه الإخبارية على الانتباه والتذكر وتم تسجيل ثلاث تجارب قامت بدراسة تأثيرات الإبداع في ضوء تفضيلات المشاهدة ووقت المشاهدة واسترجاع الذكريات وتقديرات الاهتمام. وأسفرت أول تجربتين على أنه حين نت مشاهدة الصور بأنفسهم، نظر الطلاب لفترة أطول للصور الجديدة وتذكروها بشكل أفضل

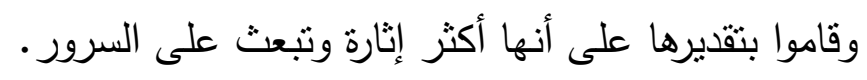




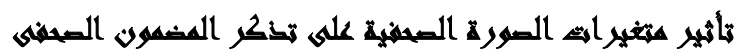

-دراسة ميرفت محمد كامل الطرابيشى (1 . . ץ) تأثنر الأشكال الصحفية فى الصحف المصرية على تذكر المعلومات السياسية لدى الثباب الجامعى. اعتمدت هذه الدراسة على المنهج التجريبى باستخدام مجموعتين أحدهما تجريبية والأخرى ضابطة بالتطبيق على خمسين مفردة من طلاب

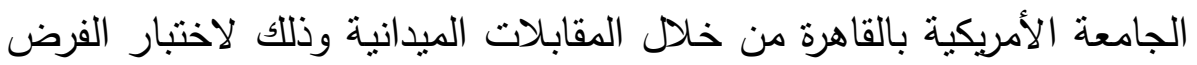

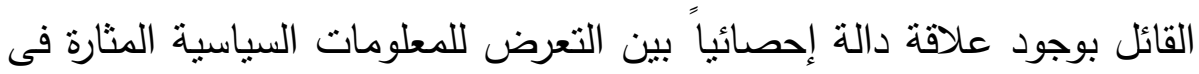
الصحف المصرية وبين درجة نذكرها واسترجاعها لدى الثباب الجامعى، وكذلك بين نوعية الأشكال الصحفية المصاحبة للمعلومات السياسية وبين درجة تذكرها وتمثيلها لدى الثباب الجامعى. وتوصلت الدراسة لعدم وجود فروق دالة إحصائياً بين الذكور والإناث فى المجموعة الضابطة وبين تذكر المعلومات السياسية فى الصحف المصرية

- دراسة سمير محمد محمود (ع ـ . rم) "تأثير المعالجة الرقمية لعناصر الثكل المرئى للصحيفة على انتباه وتذكر القراء للأخبار فى إطار نظرية تمثيل المعلومات".

اعتمدت الدراسة على المنهج التجريبى لمعرفة أثز المعالجة الرقمية للعناصر المرئية بالصحيفة بالتطبيق على الصور والأرضيات فى جذب انتباه القراء وتدعيم تذكرهم للمحتوى الخبرى وتوصلت الدراسة الى ان المعالجة الرقمية التى تجرى على الصور تؤدى لوجود فروق ذات دلالة إحصائية فى درجات الانتباه للمبحوثين وأن هذه الفروق تتباين تبعاً لنوع المعالجة الرقمية التى أجريت على الصور وكذلك ارتفاع درجة انتباه المبحوثين للمعالجات 


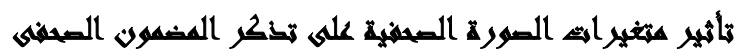

الرقمية التى أجريت على الصور وأنها تزيد من اهتمامهم وانتباههم وهذا ما أكده حوالى 9,09\% من عينة الدراسة.

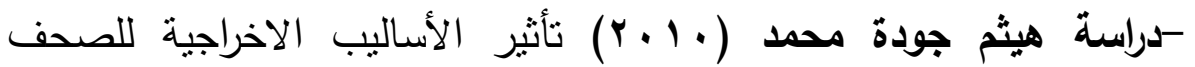

الالكترونية على العمليات الادراكية لدى عينة من طلاب الجامعة هوده هونه تهدف هذه الدراسة إلى معرفة تأثنر أساليب الإخراج للصحف رله الإليكترونية على إدراك الطلاب للمحتوى المقدم وتدعيم تذكرهم له واتجاهاتهم ( نحو الواقع ومن أهم نتائج الدراسة أن الخبر على الانترنت مكتمل العناصر صور + نص + فيديو ) هو أكثر التصميمات تذكرا لدى المتصفحين وأكثر التصميمات التي ساعدت على تمثيل المعلومات الرسائل الاخبارية -دراسة عبير محمد حمدي(11 + ب) ، تأثنير طرق العرض في ادراك وتذكر المضمون الاخباري - دراسة تجربيية مقارنة بين التليفزيون والوسائط المتعددة عبر الانترنت. هدفت هذه الدراسة إلى اختبار تأثير طرق عرض المضمون اللفظي والمرئي في الأخبار المقدمة بوسائط متعددة تفاعلية في إطار علاقتها بالصورة على اكتساب المعلومات المتضمنه في المادة الاخبارية وتوصلت الدراسة إلى لى انخفاض ملحوظ في مشاهدة التليفزيون مقارنة بالانترنت وتساعد الوسائط المتعددة المستخدمة في المواقع في زبادة معدلات الادراك ومن ثم زيادة معدلات التذكر ولم تثبت الدراسة وجود فروق ذات دلالة احصائية بين الذكور والاناث في ادراك وتذكر خبري الدراسة دراسة جو جنج Guo, Jing (2013 ) تأثثر الانفعالات والثقافة في الصور الإخبارية أون لاين على تقييم الذاكرة وخصائص النص. 'ل 
تعتبر هذه الدراسة تجربة تستكثف تأثثر تحميل الذاكرة والصور

الإخبارية من الناحية الثقافية على معالجة النص الإخباري المتتابع، وأوضحت هلته النتائج أن الصور الإخبارية بمفردها لم يكن لها تأثثر ذي دلالة على التذكر الإحيه العام للمعلومات في النص الإخباري وأكدت الدراسة أن العناصر الانفعالية والثقافية يتم تحيلها في الصور الإخبارية يمكن أن تكون بمثابة مساعدات ؤثرة تقوم على نحو مشترك بتعريف توصيف الذاكرة مشكنة الدراسة: مشكلة البحث الحالى يمكن بلورتها فى التساؤل الرئيسى التالى:- ما الدور الذى يمكن أن تقوم به الصورة الصحفية فى تدعيم عملية التذكر بالنسبة للمضمون الصحفى وعلاقة المتغيرات الخاصة بالصورة على عملية التذكر بر أهمبة الإراسة: تعد الدراسة الحالية إحدى الدراسات العربية التى تحاول سد النقص فى الدراسات التى تبحث فى التأثير المعرفى للصورة الصحفية بالنسبة للمتلقى وبيان الدور الذى يمكن أن تقوم به فى هذا الصدد من خلال

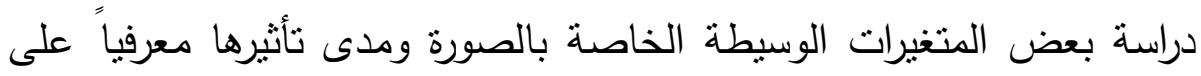
القراء.

أهداف الدراسة: تهدف هذه الدراسة إلى:التعرف على الدور الذى تقوم به الصورة الصحفية فى تدعيم المحتوى الخبرى ومعرفة تأثثر المتغيرات الخاصة بالصورة على تذكر المضمون.

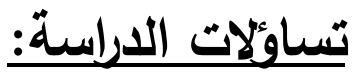

ما أفضل أشكال الصور فى جذب انتباه القراء؟ 


$$
\text { ما الأنواع التى يفضلها القراء من الصور؟ }
$$

ما أكثر العوامل التى تساعد على تذكر المضمون؟

ما أفضل أثنكال الصور التى تساعد على التذكر ؟ لفاعل

ما أفضل انواع الصور التى تساعد على التذكر ؟

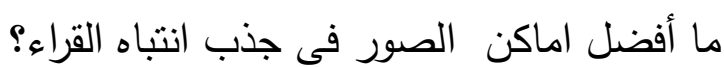

نوع الارراسة (البحث): نتدرج هذه الدراسة فى إطار البحوث الوصفية والتى تعتمد على منهج المسح بالعينة فى جمع البيانات عينة الارلسة: نم سحب عينة قوامها ( ..؛) مفردة من سكان محافظة المنيا من قراء الصحف وتم سحب العينة بالطريقة العشوائية البسيطة أدوات جمع البيانات: تستخدم الدراسة الحالية استمارة الاستقصاء كأداة لجمع البيانات الميدانية من المبحوثين حيث يقيس الاستقصاء الاتجاهات والاعتقادات والمعلومات لاى عينة البحث

\section{الصورة الصحفية}

تقف الصورة الصحفية جنباً إلى جنب مع الحروف سواء حروف المنن أو العناوين - فى نقل الرسالة الإعلامية من خلال صفحات الصحفية إلى الى

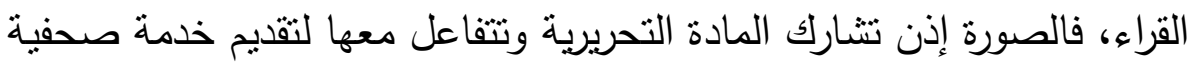
متكاملة إلى القارئ الذى لم يعد يقتتع بمجرد القراءة عن الأحداث وإنما يريد معايشتها وبخاصة أنه يعيش اليوم عصر الاتصال بالصوت والصورة من

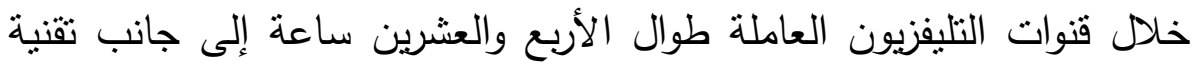
الوسائط المتعددة (Multimedia). 
حيث تتميز الصورة المطبوعة الثابتة بخاصية فربدة وهى قدرتها على

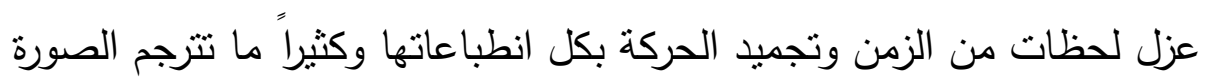
أعماق فكر الأشخاص مما يجسد الحدث أمام القارئ ويتيح لله فرصة التأمل

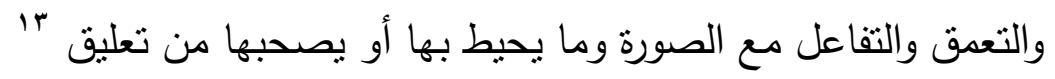
ويمكن تعريف الصورة الصحفية على أنها صورة منفردة لتغطية حدث هام تجلب المتعة للمشاهد، وتقدم معلومات كاملة وتسجل زمن الموضوع وتتجه

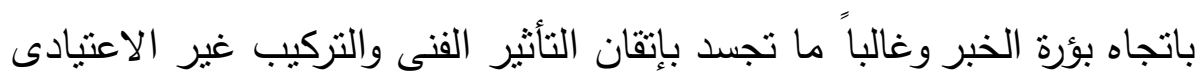

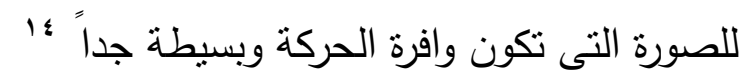
والصورة الصحفية بمفهومها الثامل هى تسجيل لانتفاضة أو حركة حصلت تقوم عدسة آلة التصوير بالتقاطها وتثثيتها على الثريط الحساس الذى يتأثز بالضوء داخل حجرة مظلمة وفى زمن أقل من الثانية وبعد طبعها وتكبيرها على الورق يحس المرء أن الزمن قد توقف عند تلك الحركة ولم يعد يتحرك ويتقدم 10

هذا وقد شهدت العشرون سنة الأخيرة من القرن التاسع عشر، تطورات تقنية سريعة اعتبرت - آنذاك- ثورة فى حقل الصحافة المصورة، شملت مجالات عديدة ولكن أعظم تطور تقنى فى ناريخ الصحافة المصورة كان عملية طباعة الصورة الظلية Halftone فقبل اختراعها لم تكن هناك طريقة عملية لنقل الصورة الفوتوغرافية مباشرة على الصفحة المطبوعة 14 وتطور استخدام الصور الصحفية حتى وصلنا إلى عصر الصحافة المصورة Pictorial Journalism وهى نوع من الصحافة يعتمد أول ما يعتمد على الصورة الصحفية وبعطى أولوية كبيرة للمصورين الذين يشكلون غالبية 
محرريها وهذا أصبحت عدسة المصور تقوق قلم المحرر فى الصحف المصورة

واليوم نادراً إن لم يكن مستحيلًا -أن نجد صحيفة- أى صحيفة تصدر بدون استخدام الصور الفوتوغرافية على الإطلاق الأمر الذى يعود فى المقام

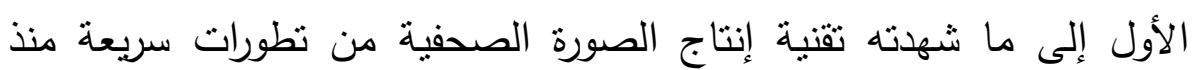

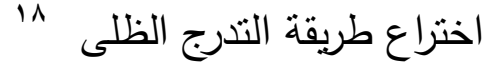

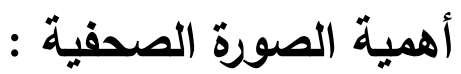
إن أهمية الصورة فى الصحافة لبست فى حاجة إلى تأكيد فهى تشارك المادة التحريرية وتتفاعل معها لتقديم خدمة متكاملة للقارئ الذى لا يقتتع بالقراءة عن الأحداث وإنما يريد معايشتها، ورغم منافسة التليفزبون للصحافة فى هذا المجال فإن الصورة المطبوعة تتميز بخاصية فريدة وهى قدرتها على عزل لحظات معينة من الزمان الثئ الذى لا تستطيعه آلة تصوير التليفزيون 19 ولاشك أن أهم وسيلة تقيس شكل الصحفية ومحتواها هى استخدام الصورة الفوتوغرافية بفاعلية كبيرة فالصورة يمكن أن تجذب القراء إلى الجريدة، وتساعد على دعم موقف الصحيفة فى المنافسة مع التليفزيون ووسائل الإعلام الأخرى

$$
\text { r. التى تتتافس من أجل الاستحواذ على وقت القارئ }
$$

كما أن الصورة الجيدة يمكن عن طريقها توصيل المعلومات إلى القراء حيث تجذبهم إلى متون القصص الخبرية التى تحتوى على المزبد من المعلومات بr حيث أن الصورة الفوتوغرافية قد تصبح أكثر أهمية من الكلمة المطبوعة وخاصة فى مجال التعليم من خلال الرؤية البصرية ويمكن أيضًا أن 


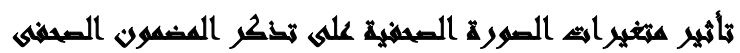

يكون التصوير الفوتوغرافى وسيلة قوية لتعليم العين وتتقيفها والارتقاء بها كوسيلة لإدراك الفنون المختلفة

\section{الصورة وتذكر المضمون :}

فى عصر تعددت فيه وسائل الإعلام وسادت فيه ثقافة بصرية جديدة، أصبحت الصورة عنصراً مهماً فى بنية الرسائل الاتصالية سواء فى الصحف وسف الإعلى المطبوعة أو الإككترونية أو فى المحطات التليفزيونية، وقد تطورت صناعة الصورة بشكل كبير فى القرن العشرين وأصبحت أداة لإبهام أسقطت الحدود

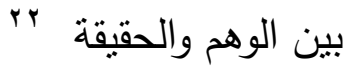

وقد أتثتت البحوث والدراسات أن الأفراد لديهم القدرة على تذكر الصورة أكثر من المادة المكتوبة فيما يعرف بظاهرة تفوق الصورة ويرجع هذا التفوق إلى أن الصورة يتم ترميزها ترميزًا مزدوجاً أحدهما لفظى والآخر تخيلى، حيث

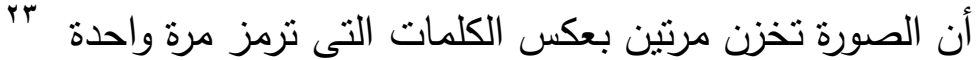
وقد أكدت عدة دراسات فاعلية الصحيفة كوسيلة بصرية وفاعلية الصور والرسوم فى جذب انتباه القراء وزيادة تذكرهم للمضمون وبشكل يفوق قدرة النصوص ذاتها على جذب الانتباه أو زيادة التذكر . ويركز التفسير السائد للوجود الأقوى للصورة فى الذاكرة على قدرتها الفائقة فى إثارة استخدام التخيل العقلى -miental imagry- العملية التى تتم من خلالها إعادة خلق المثير الذى تتم معايشته دن قبل فى ذهن الفرد فى حين

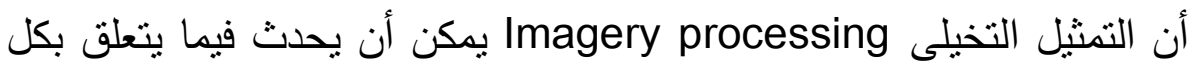
الحواس إلا أن التخيل البصرى Nisual imagery ذو صلة وثثقة بفهم تأثيرات الصورة 


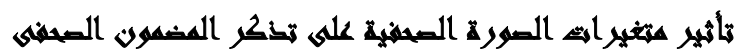

وقد توصل Laug new hagen, reeves 1998 إلى اكتشاف أن المشاهدين يكون معدل ضربات قلوبهم أبطأ أثناء مشاهدة القصص الإخبارية التى تشتمل على صور جرافيكية سلبية أكثر من مشاهدة نفس القصص

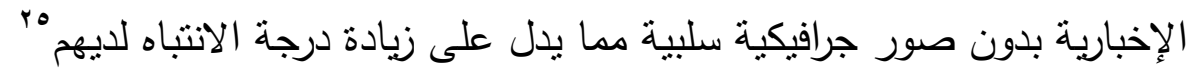
S.A. Tucker and J.V. Dempsey وأجرى تويكر وديمبسى دراسة على طلاب الدراسات العليا حول تأثنير الصور على استدعاء الذكريات وادراك معلومات النصوص المصاحبة، وأظهرت النتائج أن الصور المصاحبة. لنصوص توفر قدراً أكبر من المعلومات وأن المبحوثين قد أظهروا ميلاً للاستجابة إلى العناصر المرئية التى جلبت الذكريات أكثر وأوضحت

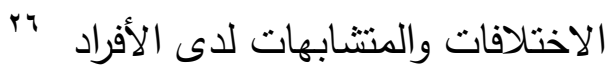

وتبقى الصورة فى الذاكرة وبقوة نظراً لقرتها على إثارة التخيل العقلى للمثير البصرى الذى يتلقاه القارئ وهو ما يتبعه تمثيل تخيلى للمواد المصورة باستذعائها من الذاكرة واعمال التخيل البصرى لفهم تأثيرات الصورة ومعانيها

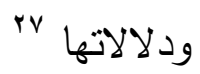

حيث أكدت دراسة بافيو Paivio أن الصور بتم تذكرها والتعرف عليها أفضل من النصوص أو الكلمات، حيث أن المعلومات يتم نقلها فى شكل بأن مصور يكون لها درجة تذكر عالية أكثر من نلك المعلومات التى يتم نقلها فى لـى شكل لفظى (النصوص)، وهذا ما يدعم ويؤكد على أن الصورة تلعب دوراً أساسيًا ومهماً فى جذب الانتباه ورفع درجة التذكر بالنسبة للنصوص اللفظية وتشمح السمات الحسية الفربدة للصور بأن يتم ترميزها بشكل أكثر تميزاً عن بن بناه

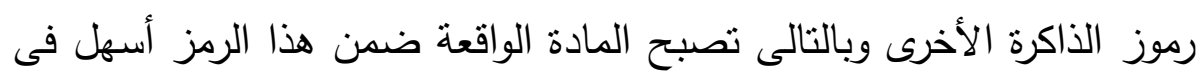


تذكرها الكلمات غير ملائمة للتميز الحسى وهكذا عندما يتم التمثيل عند مستوى حسى ضحل فابد أن يتم تعلم المادة المصورة بسهولة أكثر من المادة اللفظية فقط

حيث أن الصورة الصحفية الجيدة تجذب الانتباه وتثير الاهتمام تقدم رسائل مؤثرة في رواية خبر ما أو عرض موضوع ما في شكل لا تستطيع الكلمات وحدها أن تؤديه وينصح التيبوغرافيين بضرورة وضع صورة صحفية إلى جانب أسطر المتن خاصة بالنسبة للموضوعات المهمة والثائكة لأن هذا

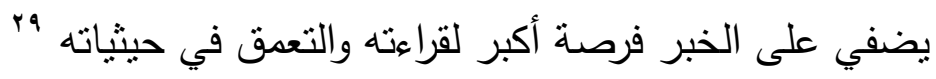
وتتمتع الصورة بخاصية مخاطبة حاسة البصر وهي الحاسة التي يعتمد الإنسان عليها في حصوله على المعلومات التي يختزنها في ذاكرته طوال حياته فالتعلم بشكل عام يعتمد على حاسة البصر ، وتعطي هذه الحاسة أهمية

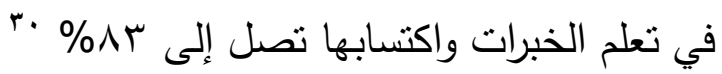
وقد بات يطلق على العصر الذي نعيشه الآن عصر الصورة كما لها من ضرورة حتمية في حياتتا اليومية وفي وسائل الاعلام المختلفة' المتغيرات الوسيطة للصورة ودورها فى جذب الانتباه والتذكر ا- مساحة الصورة : يعتقد أن يكون لمساحة الصورة كأحد المتغيرات الوسيطة للصورة دوراً فى جذب الانتباه حيث أن الصورة الكبيرة تجذب الانتباه أكثر من غيرها تبعاً لمبدأ (Bigger is Better) وقد تتاولت عدة دراسات هذا

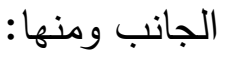

(M.Garcia, ما توصلت إلبه دراسة ماريو جارسيا، وبياجى ستارك إلى أن القراء قد جذبت انتباههم الصورة عندما نشرت على عمود P. stark) 
واحد وكانت النسبة حوالى ؟0\% من القراء، فى حين زادت النسبة لنتزاوح ما

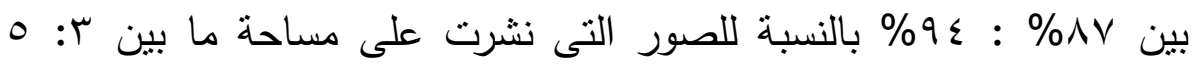
أعمدة بين

B.W. Burn ومنها أيضاً ما توصلت إليه دراسة بورت وود بورن

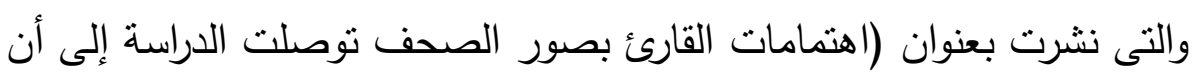

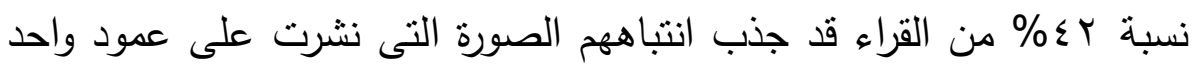

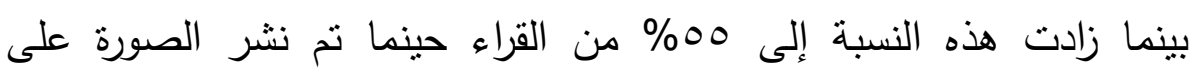

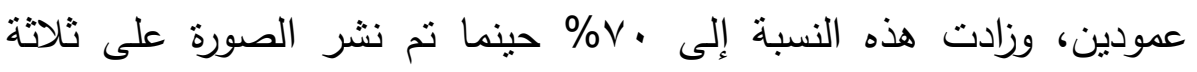
أعمدة"

وفى دراسة أخرى قام بها بولينسكى J.S. Pollansky توصل فيها

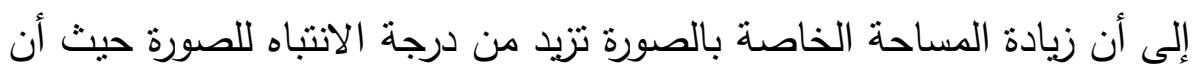
الصورة حينما نشرت على عمود واحد انتبه إليها حوالى ؟ \& ٪ بينما عندما

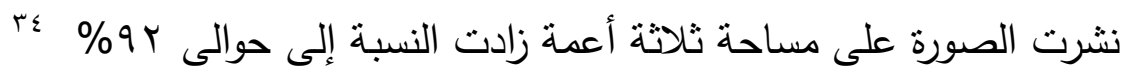

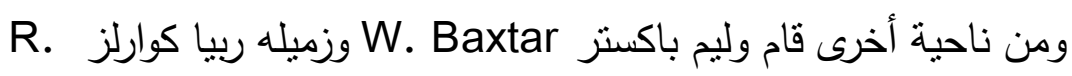
بuarles

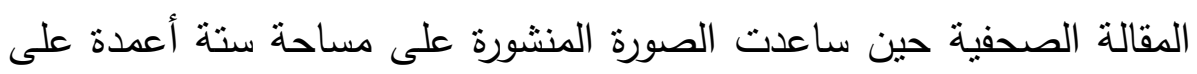
تحسين استرجاع المقال المصاحب للصورة فى حين لم تظهر الصورة المنشورة

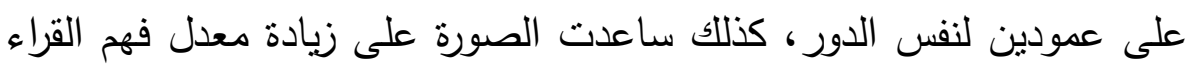

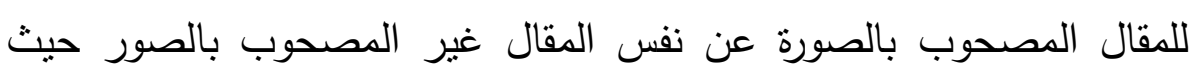

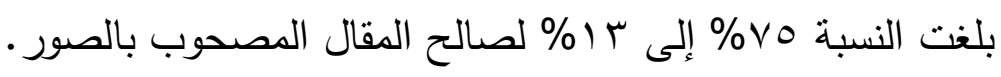




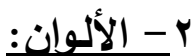

فى السنوات الأخيرة حاولت الصحف بل حرصت على الاستفادة من الألوان ومالها من تأثثرات وجدانية ونفسية على القراء وذلك من خلال استخدامها فى أغلب الصور المنثورة على صفحاتها، حيث أن إدخال الألوان إلى الصورة الصحفية يضفى عليها المزيد من الواقعية وجذب بصر القارئ بالإضافة إلى دعم موقف الصحيفة والتنافس فى مواجهة الصحف الأخرى من الصن

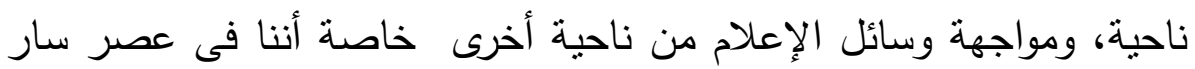

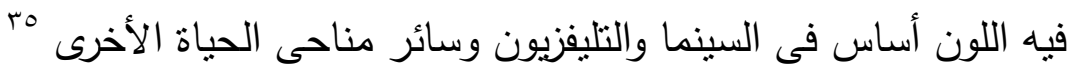
واللون يجذب الانتباه، حيث أن جذب الانتباه هو الوظيفة الأساسية

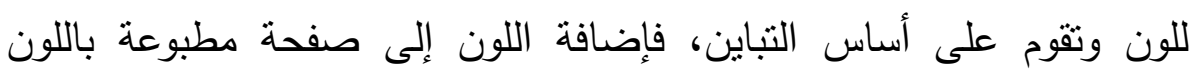

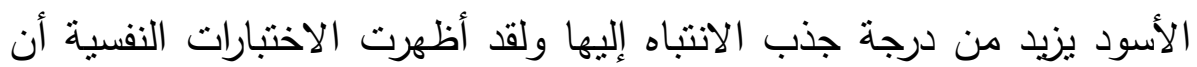

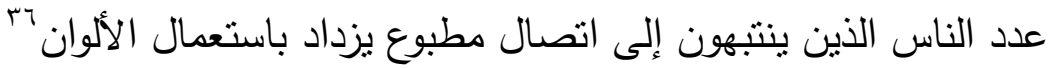
واللون يخلق حالة من التنكر حيث يميل العديد من الناس فى وصفهر لشئ ما إلى الإثارة للونه وهذا بسبب أن اللون له قيمة تذكرية عالية وذلك لأن

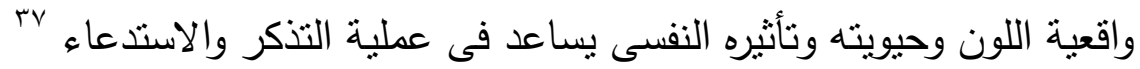
وهناك دراسات عديدة أثثتت دور اللون فى التذكر ومنها : دراسة جوزفيسون شيرى (J. Sheree) والذى قام بدراسة حول تأثير الصور الصحفية الملونة على العمليات الإدراكية للقارئ من انتباه ووعى وفهم وتذكر

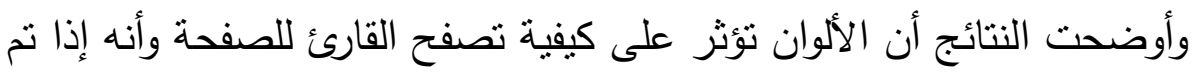
توظيفها بطريقة معينة يمكن أن تعطى الأثر المرجو كما أكدت الدراسة الدأه 


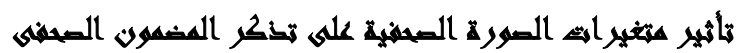

ونتائجها أن استخدام الألوان يؤثز فى فهم واستيعاب الصور الصحفية بصورة عامة

K.Gilberts, J.Schleuder وفى دراسة قام جلبرت وشولدر

( • (199) حول بحث تأثيرات اللون والتعقيدات فى الصور على المجهود الذهنى والذاكرة، حيث توصلت هذه الدراسة إلى أن اللون يحسن التعلم والذاكرة حيث وجد أن اللون ذو تأثير عال فى تحديد الموضوعات وأن الناس يعتمدون على اللون بشكل أكثر فى تحديد الملامح الإدراكية للأشياء، حيث أثنارت النتائج التجريبية إلى أن التعرض لصور ذات عناصر ملونة أو مركبة ينتج عنه استجابات مختلفة للمشاهد أكثر من الصور الأسود وأبيض أو البسيطة وتم الاستدلال على أن اللون يزيد سرعة معالجة الصورة والتعقيد يزيد من تذكر

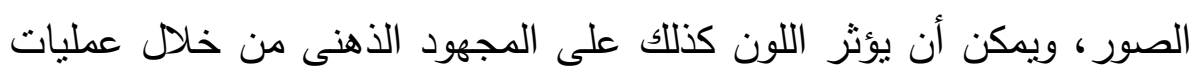
الذاكرة، وبناء على ذلك فإن الاستخدام الواسع للون فى الصحف قد يفيد الصحفيين الذين يريدون لمن ينظر إلى الصورة أن يفهمها بسرعة وسهولة نظرية تمثيل المعلومات

أخذت نظريات الإعلام بعد انتهاء الحرب العالمية الثانية اتجاها معرفيا حيث بدأ العلماء بوضع أسس ومناهج تثتاول مجال المهارات العقلية والانسانية والاجتماعية وتجسد ذلك في ظهور نظرية تمثيل المعلومات التي تعد فرعا من فروع علم الاتصال والتخاطب والتي تمدنا بطريقة مجردة لتحليل عمليات تمثيل المعلومات عند الانسان . •

ولأكثز من عقدين طور علماء النفس المعرفي نظرية تدور حول الطريقة المعتادة التي يتعامل بها الأفراد مع المعلومات الحسية أو ذات العلاقة 
بالحواس وهي نظرية تمثيل المعلومات التي دمجت بين علم النفس المعرفي

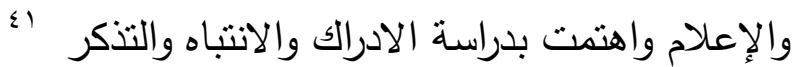

وكانت التطورات التى شهدها عالم الكمبيوتر منذ الخمسينات عاملاً

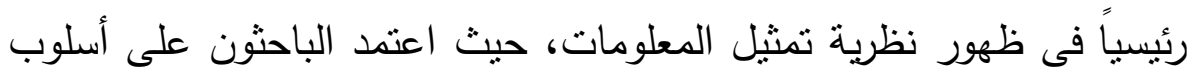

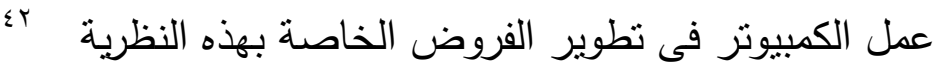
هذا وقد أوضحت هذه النظرية أن الذاكرة تقوم بمعالجة المعلومات

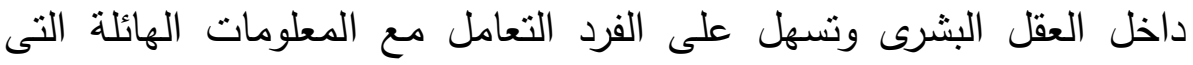

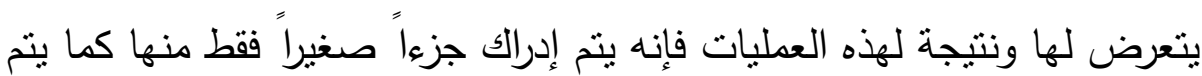
تخزين جزء أصغر فى الذاكرة طويلة المدى (وهى ذاكرة ذات سعة غير محدودة تتنقل إليها المعلومات وتحتفظ بها لفترات طويلة وقد لا تقفدها أبداً. هذا وقد تفردت هذه النظرية بالتمييز بين عمليتين معرفيتين يحدثان

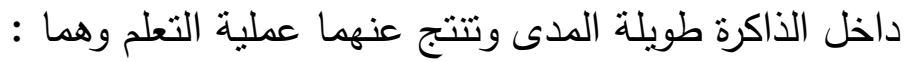

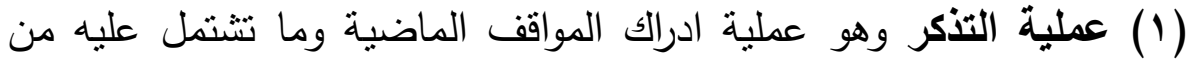
خبرات وأحداث فالذاكرة هي إحدى الوظائف العقلية المختصة باختزان

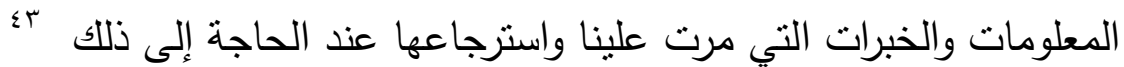
ويحدث النسيان عند الفثل في أداء وظيفة التذكر أي عدم القدرة على اختزان المعلومات والمعارف التي تعلمناها أو عدم القدرة على استرجاعها عند الحاجة إليها ؛ ؛

(Y) عملية فهم المعلومات وهى عملية تكامل بين المعلومات القادمة الجديدة والمختزنة فى الذاكرة من قبل حيث نستخدم المعلومات السابق تخزينها فى لئ

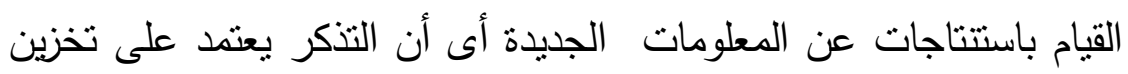


بسيط للمعلومات فى حين يعتمد الفهم على تخزين أكثر تعقيداً حيث تضاف

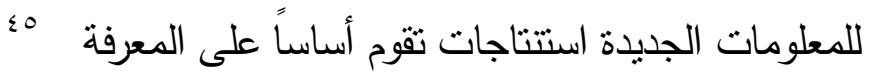
ويشير Woodall إلى أن حدوث إحدى هاتين العمليتين ليس دليلاً على حدوث الأخرى وأن سهل وقوعها. ويختلف الفهم عن الادراك فالادراك مرتبط بالمنبهات في العلم الخارجي أما الفهم فهو مرتبط بالعمليات المعرفية، فهما مختلفان لكنهما غير منفصلين حيث أن الفهم يبدأ بالادراك وينتهي بالاستيعا بـاء الانتباه:

الانتباه هو نركيز الجهد العقلي على أحداث حسية أو عقلية فهو عملية انتقائية لمثيرات أو منبهات معينة يتم اختبارها وتركيز العمليات المعرفية عليها حيث يسمح الانتباه بأن نضع في بؤرة الشعور ماهو مهم في اللحظة الحالية

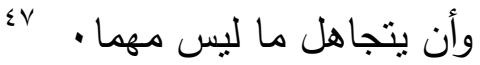

كما يعد الانتباه عملية عقلية تهدف إلى حصر النشاط الذهني في اتجاه معين مدة من الزمن من خلال القدرة على التحكم في النشاط الانفعالي

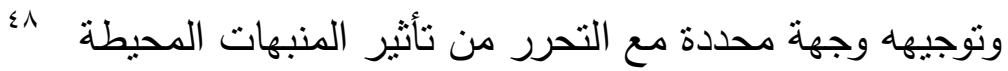
وكما يعد الانتباه الموضوع الرئيسي أو المرتبط ارتباطا وثيقا بعملية الوعي بالنسبة لموضوع الرسالة الإعلامية وتذكرها ويوجد نوعان من الانتباه هما الانتباه الخاضع للسيطرة والانتباه التلقائي ويكون الانتباه الخاضع للسيطرة مرادفا للجهد الذهني ولا يستلزم الانتباه الانتقائي استخدام موارد محدودة ويتم

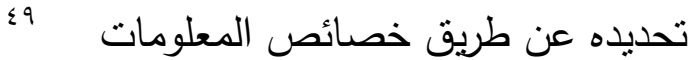


وبالتالى فإنه حسب هذه النظرية نجد أن الفرد يكون مدركاً أو واعياً لجزء صغير من المعلومات التى تقدم فى البيئة حيث يمتص كمية كبيرة ويدرك جزء انه هغير منها منير المعلمات

وساهت هذه النظرية في إضافة رصيد علمي لتفسير بناء المعاني

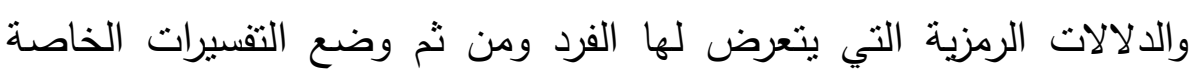

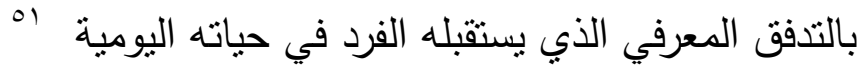

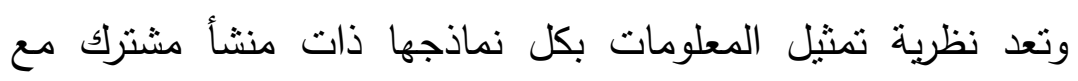
نظرية تحليل الاطار فكلاهما يعد من نظريات دراسة التأثير المعرفي للأخبار

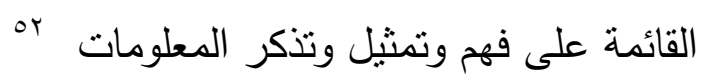

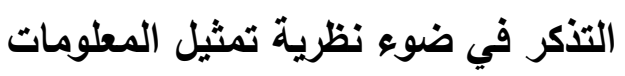

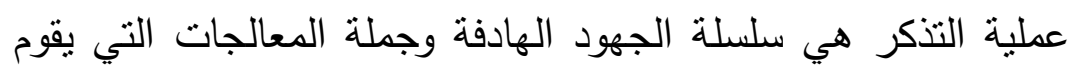
بها الثخص المتذكر منذ لحظة انتهاء مهمة الادراك وربما قبل ذلك بقصد

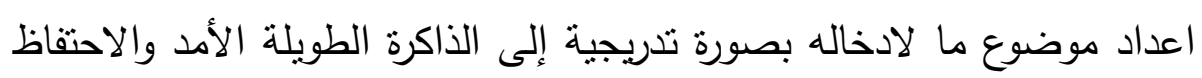

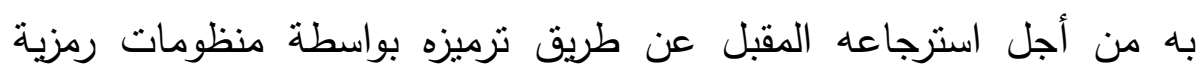

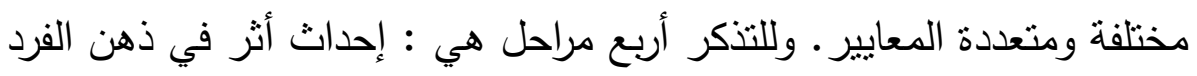

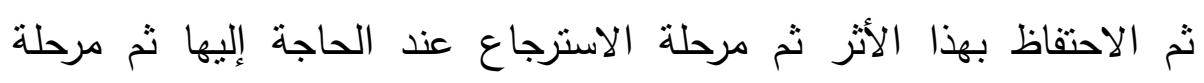
الاحتفاظ. الاحت or

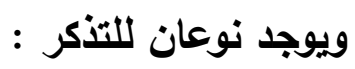

1- تذكر لا إرادي: وهو الذي يحدث دون تدخل إرادة الفرد وهو تذكر موضوع

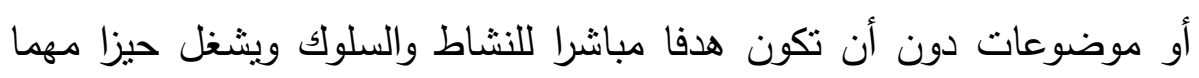




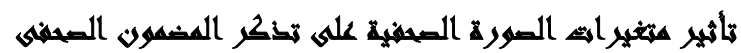

في حياة الإنسان ويكون الثكل الرئيسي والوحيد للتذكر في مراحل الطفولة الأولى ثم يتراجع مع النمو ليحل محله التذكر الإرادي. r-تذكر إرادي: يقوم به الثخص بنفسه في الوقت الذي يريده وهو نتاج الأفعال التذكرية الخاصة أي ثمرة لتلك الأفعال التي يكمن هدفها الأساسي في لي لئه

\section{نتائج الاراسة}

ا - العوامل المتعلقة بتذكر المضمون.

جدول (1) بعض العوامل المتعلقة بتذكر المضمون لأفراد عينة البحث

\begin{tabular}{|c|c|c|c|c|c|c|c|c|c|c|}
\hline \multirow{3}{*}{ 䨒” } & \multirow{3}{*}{ كا' } & \multirow{3}{*}{\begin{tabular}{|c|} 
النسبية \\
\%
\end{tabular}} & \multirow{3}{*}{ المبن } & \multicolumn{6}{|c|}{ الآراء } & \\
\hline & & & & \multicolumn{2}{|c|}{ لا أوافق } & \multicolumn{2}{|c|}{ إلى حد ما } & \multicolumn{2}{|c|}{ أوافت } & \\
\hline & & & & $\%$ & ك & $\%$ & ك & $\%$ & ك & \\
\hline 7 & $"|A|, \mid, 4$ & $|r 0, r T|$ & $V \wedge \varepsilon$ & $19,0$. & $\mathrm{v \Lambda}$ & $10, \ldots$ & |r. & $10,0$. & 4 & أقراه في الصحفى استرجاع ما \\
\hline 1 & "1 & $\Lambda 1,1 \mathrm{v}$ & $9 \vee \varepsilon$ & $0,0$. & rr & $\leqslant 0,0$. & $|A r|$ & $\leqslant 9, \ldots$ & 197 & 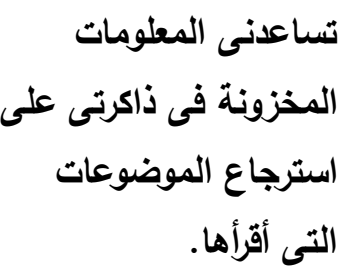 \\
\hline r & $" \wedge ৭, \vee \wedge$ & $\mathrm{Vv}, \wedge \mathrm{r} \mid$ & $94 \leqslant$ & $11, .$. & ؛ & $\leqslant \leqslant, 0$. & IVA & $\leqslant \leqslant, 0$. & ivi & أسأخبار أخرى حتى الأخبار التى أقرأها \\
\hline$\wedge$ & $11 \leqslant,+1$ & $\Delta v, \cdot \wedge \mid$ & 110 & $r \wedge, r$. & 104 & or,r. & $r .9$ & $9,0$. & $r \wedge$ & قرأتها فى الصحفى المطومات التى \\
\hline
\end{tabular}




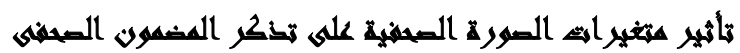

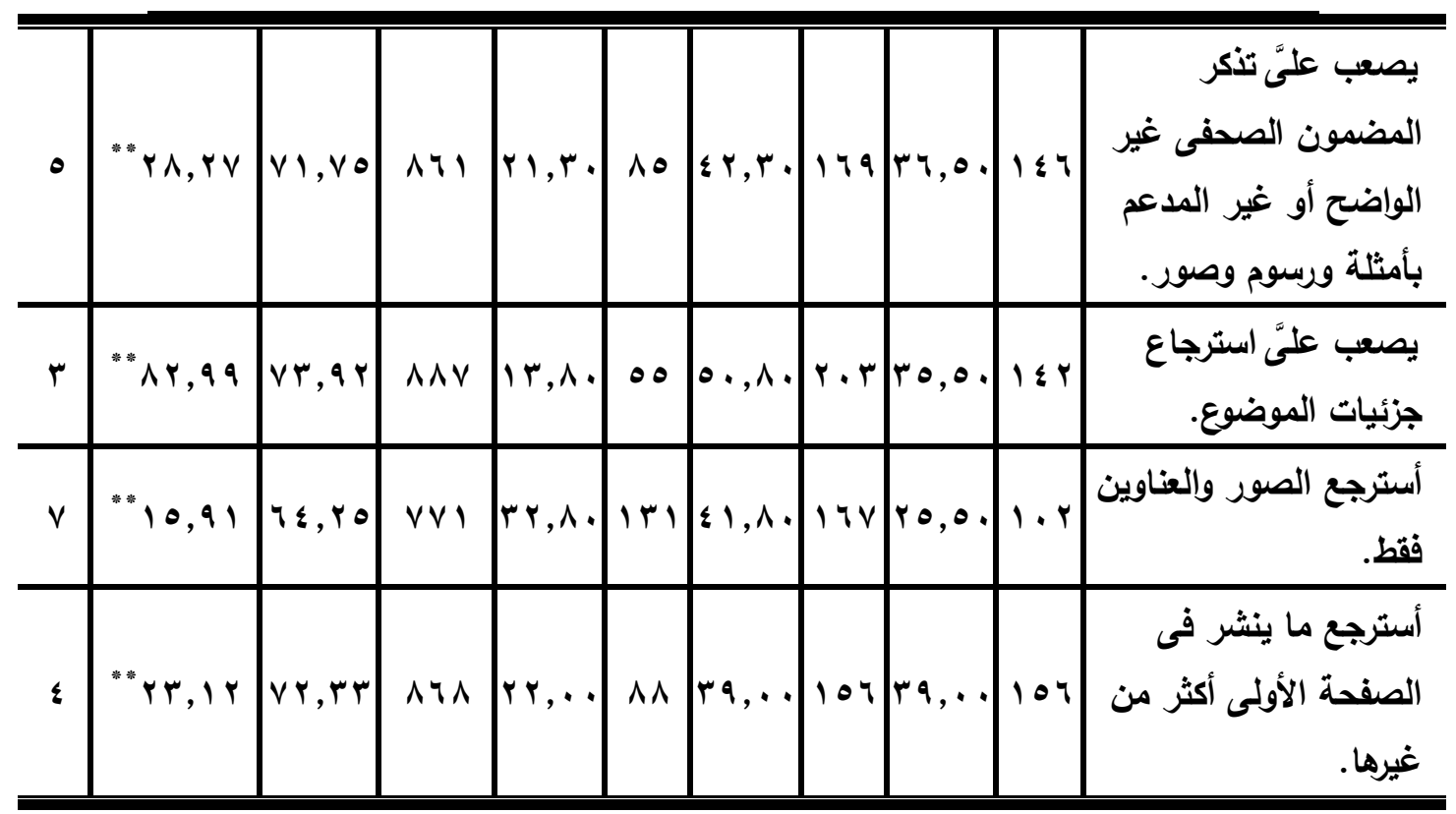

باستخدام الوزن النسبى والنسب المئوية يتضح أن النسب المئوية

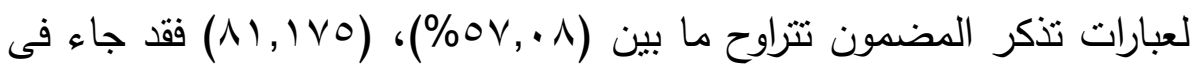
الترتيب الأول عبارة تساعدنى المعلومات المخزونة فى ذاكرتى على استرجاع

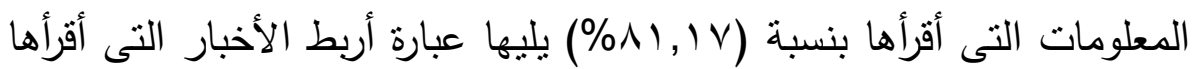
بأخبار أخرى حتى أستطيع استرجاعها بنسبة (سV,NY\%)، يليها عبارة يصعب

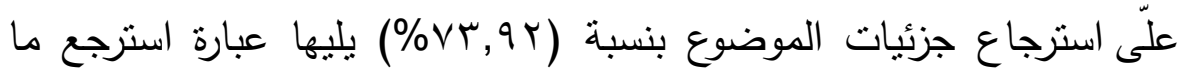
ينشر فى الصفحة الأولى أكثر من غيرها بنسبة (س,\%Y\%) يليه عبارة يصعب علّى تذكر المضمون الصحفى غير الواضح، أو غير المدعم بأمثلة

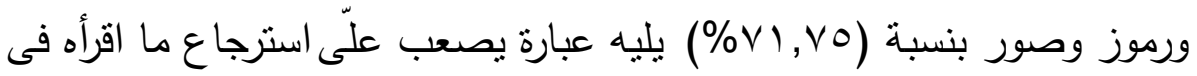
الصحف بنسبة (rr\%,\%)، يليه عبارة أسترجع الصور والعناوين فقط بنسبة 


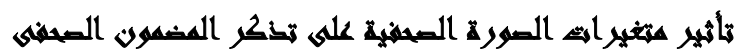

(\%) يليه عبارة أنس المعلومات التى قرأتها فى الصحف بنسبة (\%)

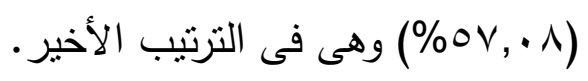

وهذا وتتسق نتائج هذه الدراسة مع دراسة محمد عبدالغني حول تعامل الصفوة مع الصحافة فيما يخص الجدوى المعرفية لوسائل الاعلام في تأكيد تفوق الصحف في اكساب الجمهور للمعلومات وفي تذكرة لهذه المعلومات

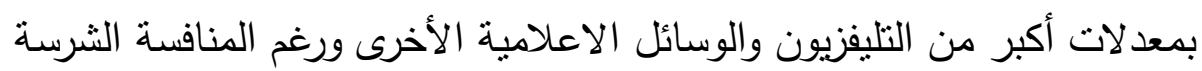

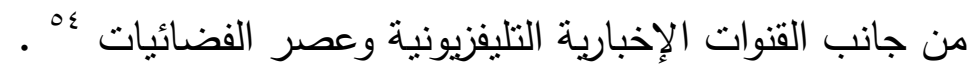

Melvin وفى ذات السياق جاءت دراسة ميلفن دي فيلير L,Defleeur

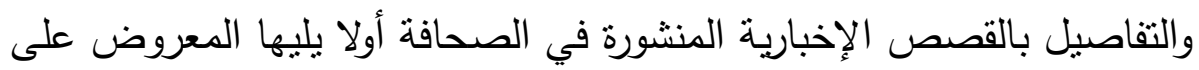
شانشات الكمبيوتز ثم التليفزيونية وأخيرا الدذاعة على الراديو

فمن خلال نتائج الجدول السابق يتضح ضرورة وأهمية الصور والرسوم فى المساعدة على تذكر المضمون بالإضافة إلى أهمية المعلومات المخزونة

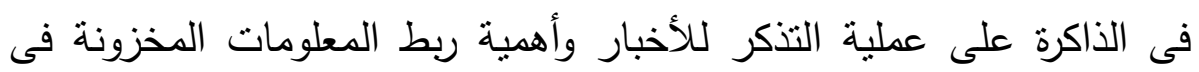
الذاكرة على عملية التذكر وأهمية ما تلعبه الصفحة الأولى وما لها من قدرة على تدعيم عملية التذكر للمضمون الصحفى. 


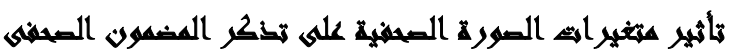

r - أهمية الصورة والدور الأى تلعبه بجانب المضمون: جدول (Y) آراء أفراد عينة البحث فى الاور الأى يمكن أن تلعبه الصورة

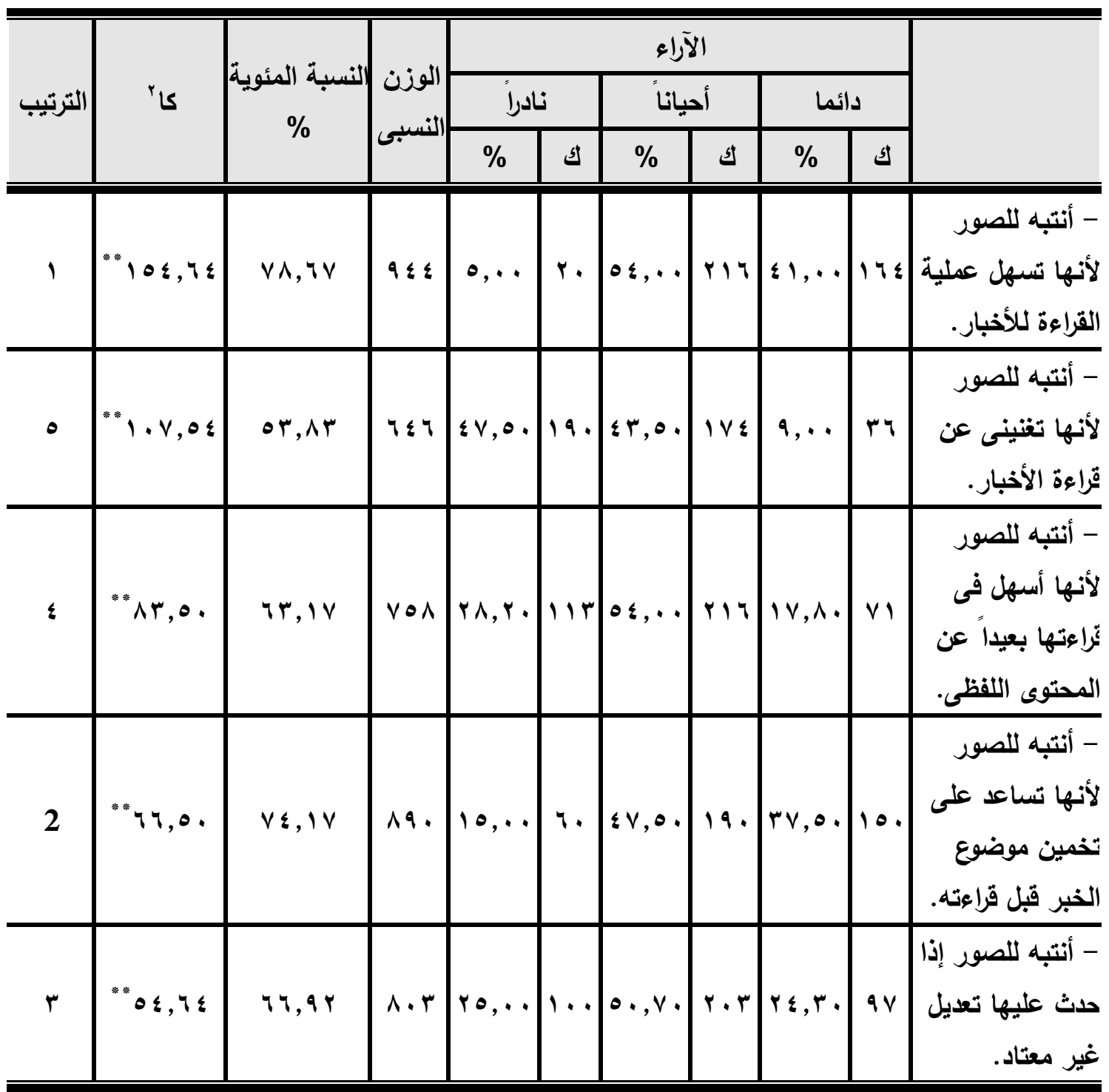


وباستخدام التكرارات والأوزان النسبية، احتلت المرتبة الأولى عبارة انتبه الصورة لأنها تستعمل عملية القراءة للأخبار بوزن نسبى (ع 9 9) وبنسبة مئوية يليها عبارة انتبه للصورة لأنها تساعد على تخمين موضوع الخبر (V^,TV)

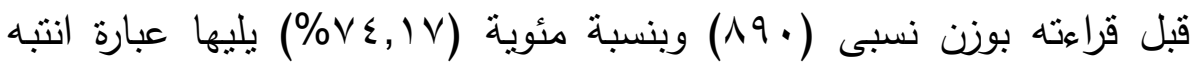
للصور إذا حدث عليها تعديل غير معتاد بوزن نسبى (r) وبنسبة مئوية

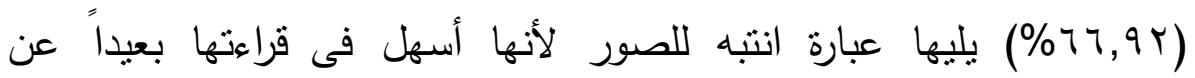
المحتوى اللفظى بنسبة مئوية (V,IV\%) وبوزن نسبى (VON) يليها أخيراً عبارة انتبه للصور لأنها تغنينى عن قراءة الأخبار بوزن نسبى (7 آ7) وبنسبة

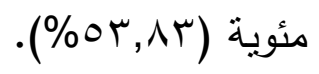

فالقارئ في القرن العشرين لا يقتع فقط بما تقوله الكلمات عن حدث بل يربد أن يعرف الصورة التي حدث بها والكتابات السهلة تعتمد على الصور والجداول والرسوم التوضيحية لتقرب المعنى إلى الأذهان ولنتوق القارئ إلى بـى المادة المقروءة ولتثير اهتماماته وتحفز ميله وله ولذا يجب على وسائل اعلام الدول خاصة تلك التي في طريق النمو حيث تكثر الأمية أن تكثر من استخدام الصورة الصحفية حتى يتسنى لغالبية

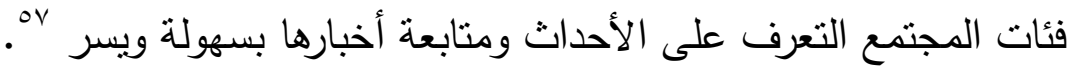
فالصورة ليست الآن بألف كلمة كما يقول المنل الصيني القديم بل بملايين الكلمات فقد ذكرت دراسات عديدة تبين أن الناس يتذكرون ( \% فقط مما يسمعونه و ، ب\% فقط مما يقرعونه في حين يصل مايتذكرونه من بين ما يرونه أو يقومون به إلى .^^\% ويقول الكاتب الروائي ايفان تورجنيف في روايته آباء وأبناء إن الصورة الواحدة قد تعرض ما استطاع كتاب أن يقوله في 


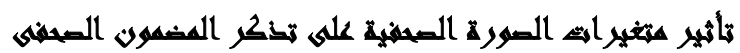

مائة صفحة (O^) ،ورغم هذا التحمس البالغ لأهمية الصورة والرأي الذي يقلل من أهمية الصورة والذي جانبه الصواب تبقي حقيقة أن الصورة الصحفية هي أكثر مايعطي روية دقيقة للحدث وخير دليل على صدق الموضوع المقدم 09

r-ثأثير شكل الصورة على تذكر المضمون. جدول (ب) تأثير شكل الصورة على تذكر المضمون

\begin{tabular}{|c|c|c|c|}
\hline الترتيب & النسبة \% & ك5 & \\
\hline 1 & $79, Y 0$ & rVV & نعم \\
\hline \multirow[t]{2}{*}{$r$} & $r \cdot, v_{0}$ & Irr & $y$ \\
\hline & $1 \cdots$ & $\varepsilon \ldots$ & الإجمال \\
\hline
\end{tabular}

وباستخدام التكرارات والنسب المئوية يتضح الآتى:- بلغت نسبة

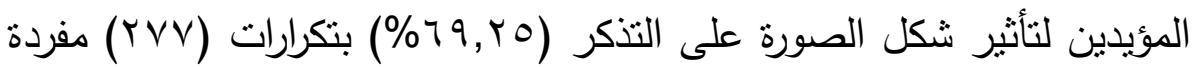
فى حين بلغت نسبة المعترضين على تأثير شكل الصورة على التذكر

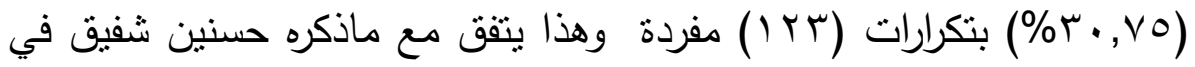
أن شكل الصورة يؤدي دورا كبيرا في جذب الانتباه وبالتالي التذكر وهو مايدفع المخرجين إلى التيقن من شكل الصورة سعيا وراء تحقيق أكبر قدر من جذب الانتباه ولذلك لا تخضع عملية تحديد الصورة لرغبة المخرج بشكل مطلق حيث يقوم بناء الصورة على التوافق الدقيق بين الثكل بكل عناصره والمضمون الذي يحدده الموضوع المرتبط بالصورة وعوامل جذب الانتباه لج 


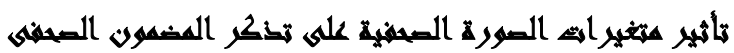

ع-أفضل الأثثكال التى تجذب الانتباه.

جدول (ع) أكثر الأشثكال التى تجذب الانتباه

\begin{tabular}{|c|c|c|c|}
\hline الترتيب & النسبة \% & ك5 & \\
\hline r & $r \cdot, q$ & $\bullet \wedge$ & الشكل المستطيل. \\
\hline 1 & $\varepsilon \mu, V$ & $|r|$ & الثكل المريع. \\
\hline$r$ & $1 \wedge, \wedge$ & or & الشكل البيضاوى. \\
\hline \multirow[t]{2}{*}{$\varepsilon$} & 17,7 & $\varepsilon 7$ & الشكل غير منتظم الأبعاد. \\
\hline & $1 \cdots$ & $r V V$ & \\
\hline
\end{tabular}

ويتضح من خلال الجدول ما يلى:- باستخدام التكرارات والنسب

المئوية جاء فى المرتبة الأولى من حيث أكثر الأشكال جذباً للانتباه الثكل

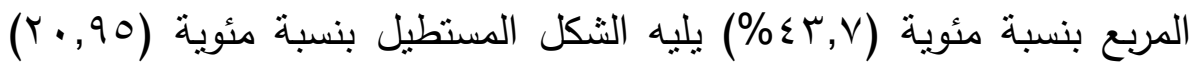
يليه الثكل البيضاوى بنسبة مئوية (1,^) (\%) وأخيراً الثكل غير منتظم الأبعاد بنسبة (7,7 ( 1\%).هذا وقد ذكر حسنين شفيق أن الثكل المستطيل هو أفضل الأشكال جذبا للانتباه في حين ذكر أن الثكل المربع من الأشكال التي يفضل الابتعاد عنها قدر الإمكان لأنه يوحي بالجمود. وأن الثكل البيضاوي يستخدم

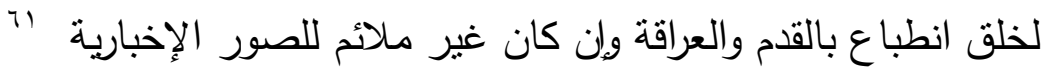




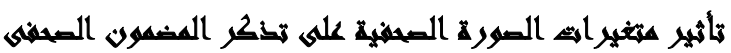

0- الأثكال التى تساعد على التذكر.

جدول (0) أكثر أشكال الصورة التى تشاعد على تذكر المضمون.

\begin{tabular}{|c|c|c|c|}
\hline الترتيب & النسبة \% & ك5 & \\
\hline r & $r 0, Y$ & VI & الشكل المستطيل. \\
\hline 1 & $\varepsilon Y, Y_{0}$ & $11 \mathrm{~V}$ & الشكل المربع. \\
\hline$\varepsilon$ & 10,00 & $\varepsilon r$ & الشكل البيضاوى. \\
\hline \multirow[t]{2}{*}{ r } & 17,7 & $\varepsilon 7$ & الشكل غير منتظم الأبعاد. \\
\hline & $1 \ldots$ & $r V V$ & \\
\hline
\end{tabular}

باستخدام التكرارات والنسب المئوية جاء فى المرتبة الأولى من حيث

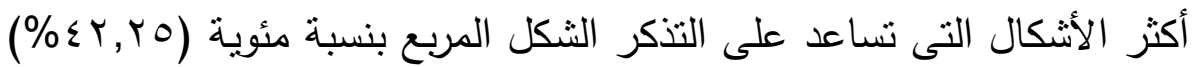

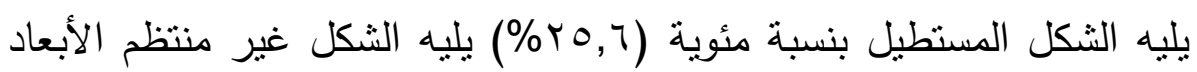

بنسبة (7,7 ( 1\%) وأخيراً الثكل البيضاوى بنسبة (0,00 (1\%).

צ- ثأثير مكان الصورة على تذكر المضمون:

جدول (†) تأثير مكان الصورة على تذكر المضمون،

\begin{tabular}{|c|c|c|c|}
\hline الترتيب & النسبة \% & 5 & \\
\hline$Y$ & $1 \wedge, 0$. & $V \varepsilon$ & دائماً \\
\hline 1 & & roo & أحياناً \\
\hline \multirow[t]{2}{*}{$r$} & I v, vo & VI & لا يؤثز \\
\hline & $1 \ldots$ & $\varepsilon \ldots$ & الإجمالح \\
\hline
\end{tabular}




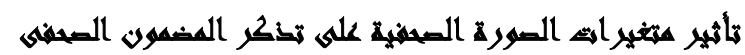

وباستخدام التكرارات والأوزان النسبية يتضح ما يلى:- جاء فى المرتبة

الأولى فى كون مكان الصورة يؤثز على تذكر المضمون أحياناً بنسبة مئوية

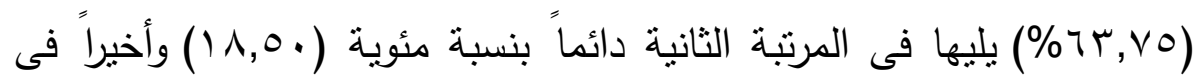
المرتبة الثالثة لا يؤثر بنسبة مئوية (V,V0) حيث ان الصورة ترتبط ارتباطا مكانيا بالموضوع الذي تصاحبه فهما يكونان معا وحدة متكاملة ويتفاعلان معا لتقديم ونقل الرسالة الاعلامية إلى القارئ وفقدان الرابطة المكانية بينهما يلغي

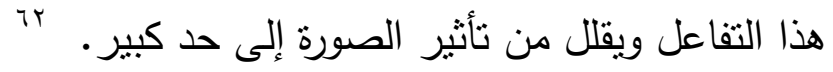

V-أكثر أماكن الصور جباً نلانتباه: جدول (V) أكثر الأماكن التى توضع فيها الصور جذباً للانتباه.

\begin{tabular}{|c|c|c|c|c|c|c|c|c|}
\hline \multirow{2}{*}{ الترتيب } & \multirow{2}{*}{$\begin{array}{c}\text { النسبة } \\
\%\end{array}$} & \multirow{2}{*}{ النسبى } & \multicolumn{5}{|c|}{ الترتيب } & \\
\hline & & & ○ & $\varepsilon$ & $r$ & r & 1 & \\
\hline r & $r r, \varepsilon$. & $1 \leq \cdot \varepsilon$ & $\leqslant r$ & $v_{1}$ & 71 & vo & $1 \leqslant r$ & أسفل العنوان. \\
\hline 1 & $r r, 0$. & $1 \leq 1$ & $0 \leqslant$ & or & V & 79 & lor & فوق العنوان. \\
\hline$r$ & $r r, A$ & IrAo & rq & $\bullet \wedge$ & $\wedge \wedge$ & 171 & $7 V$ & جانب الموضوع. \\
\hline 0 & $I r, \wedge 0$ & VVI & $I V V$ & Irr & Tr & r^ & 1. & أسفل الموضوع. \\
\hline$\varepsilon$ & $I V, I V$ & $1 \cdot r$ & $1 \ldots$ & 99 & 1.9 & $v$. & $r \wedge$ & وسط الموضوع. \\
\hline & $1 \ldots$ & $7 \ldots$ & $\varepsilon \ldots$ & $\varepsilon \ldots$ & $\varepsilon \ldots$ & $\varepsilon \ldots$ & $\varepsilon \ldots$ & جمالي \\
\hline
\end{tabular}

باستخدام الأوزان والنسب المئوية جاء فى المرنبة الأولى من حيث أكثر أماكن الصورة جذباً للانتباه موضع فوق العنوان بوزن نسبى (ع أع ( )

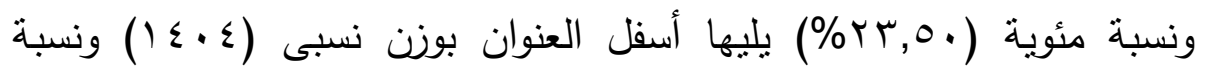




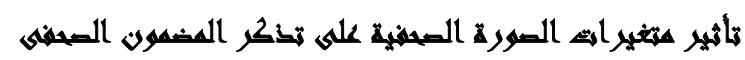

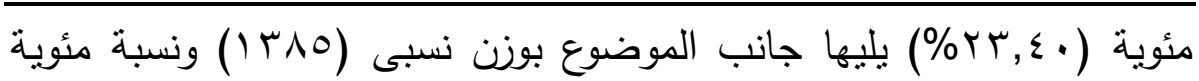

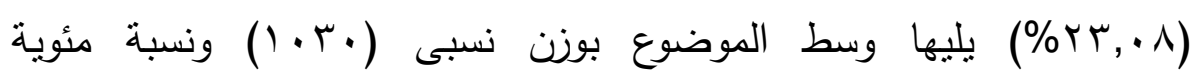
وأخيراً موضع أسفل الموضوع بوزن نسبى (VVIV, V V)

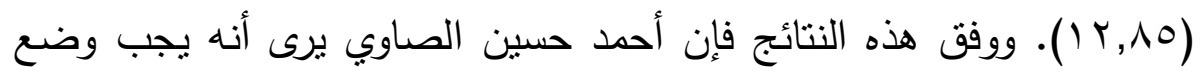
الصورة داخل النص أو بالقرب منه حتى لا يختلط الأمر على القارئ في ربطها بالمضمون، ولما كانت الصورة تجذب الانتباه أكثر من الكلمة وجب الموازنة بينهما إذ ينبغي أن توضع الصورة في المكان الذي لا يثثير انتباه

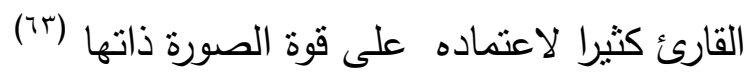

1-الأماكن التى تساعد على تذكر المضمون. جدول (^) آراء عينة البحث حول الأماكن التى يمكن أن توضع فيها الصورة وتساعد على التذكر

\begin{tabular}{|c|c|c|c|c|c|c|c|c|}
\hline \multirow{2}{*}{ الترتيب } & \multirow{2}{*}{ النسبة } & \multirow{2}{*}{ النسبى } & \multicolumn{5}{|c|}{ الترتيب } & \\
\hline & & & 0 & $\varepsilon$ & $r$ & r & 1 & \\
\hline$r$ & rr,qr & IrV & $\varepsilon \varepsilon$ & $v_{1}$ & $\wedge$. & VV & $\mid r k$ & أسفل العنوان. \\
\hline$r$ & $r r, \leqslant 0$ & $1 \leq .7$ & 9. & $\varepsilon r$ & $\Lambda r$ & $7 \varepsilon$ & lor & فوق العنوان. \\
\hline 1 & $r r, v o$ & $1 \leqslant r \leqslant$ & $r$. & $\{1$ & $\wedge 9$ & 100 & 10 & جانب الموضوع. \\
\hline 0 & $I r, r v$ & $V \leqslant r$ & INr & Irr & 0 & rq & 7 & أسفل الموضوع. \\
\hline$\varepsilon$ & $|v, 0|$ & 1.0. & $\wedge \wedge$ & 11. & 90 & $\vee \wedge$ & rq & وسط الموضوع. \\
\hline & $1 \ldots$ & 0999 & $\varepsilon \cdot \varepsilon$ & एवq & $\varepsilon \ldots$ & $\varepsilon \ldots$ & $\varepsilon \ldots$ & الإجمالي \\
\hline
\end{tabular}




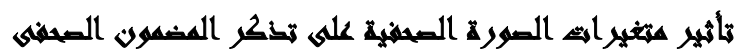

وباستخدام الأوزان النسبية والنسب المئوية يتضح الآتى:- جاء فى

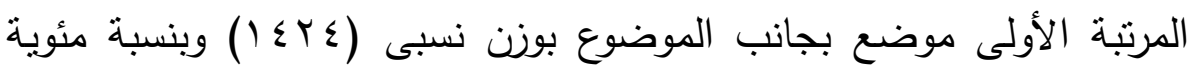

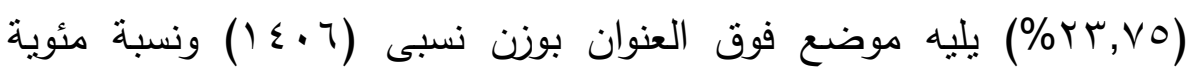

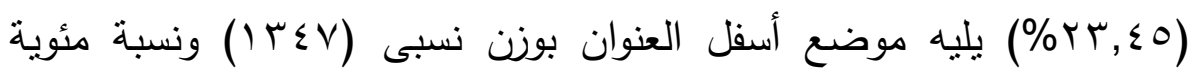

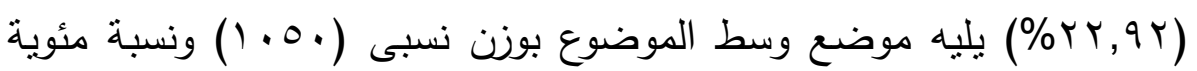

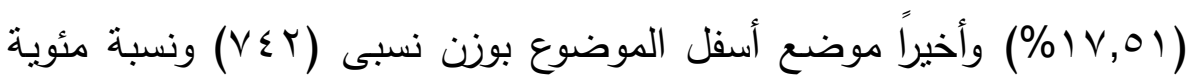
$\cdot(\%, r, r v)$

9-تأثير نوع الصورة على تذكر المضمون. جدول (9) تأثير نوع الصورة على تذكر المضمون

\begin{tabular}{|c|c|c|c|}
\hline الترتيب & النسبة \% & 5 & \\
\hline$r$ & $r \varepsilon, 0$. & $9 \wedge$ & دائماً \\
\hline 1 & $V \cdot, r_{0}$ & rAl & أحيانا \\
\hline \multirow[t]{2}{*}{$r$} & $\bullet, Y 0$ & Y & نادرا \\
\hline & $1 \ldots$ & $\varepsilon \ldots$ & الإجمال \\
\hline
\end{tabular}

باستخدام التكرارات والنسب المئوية يتضح الآتى جاء فى المرتبة

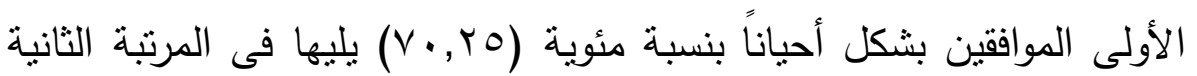

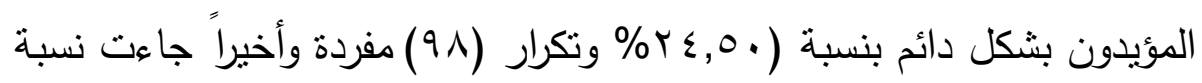
غير الموافقين بنسبة (0, 0,\%) وتكرارات (Y) مفردة. 


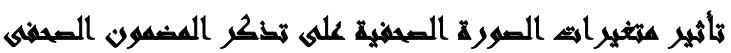

• 1 -أفضل الصور التى تساعد على تذكر المضمون. جدول ( • 1) أفضل الصور التى تساعد على تذكر المضمون

\begin{tabular}{|c|c|c|c|}
\hline الترتيب & النسبة \% & ك5 & \\
\hline$r$ & $r r, \Lambda$. & 90 & شخصية \\
\hline 1 & $99, Y$. & YVV & موضوعية \\
\hline \multirow[t]{2}{*}{$r$} & $v, \ldots$ & rA & مفرغة \\
\hline & $1 \ldots$ & $\varepsilon \ldots$ & الإجمالي \\
\hline
\end{tabular}

ويتضح من الجدول الآتى: باستخدام التكرارات والنسب المئوية جاء فى

المرتبة الأولى من حيث أفضل الأنواع التى تشاعد على نذكر الصورة

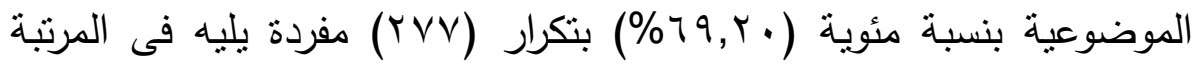
الثانية الصورة الثخصية بنسبة (.^,rr\%) وتكرار (90) مفردة يليه الصرة

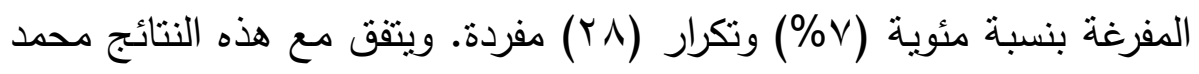

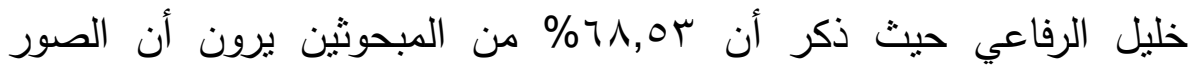
الموضوعية أكثر أهمية من الصور الثخصية في حين ذكر V乏, اسب\% أن الصور الثخصية هي الأهم، فالصور الموضوعية بلا شك أكثر إقناعا من هن الصور الثخصية وبالتالي فالصور الموضوعية تحتل مساحات أكبر في الصحف 


\section{توصيات: الاراسة وما تثيره من دراسات مستقبلية}

- عمل دراسات لبحث نأثير الصفحات الأولى والأخيرة من الصحف

على عملية التذكر .

- اجراء دراسات خاصة بالتصفح الالكتروني للصحف ومقارنته بالقراءة

التقليدية وتأثير ذلك على تذكر المضمون.

- اجراء دراسات خاصة بتأثنرات الألوان على عملية التذكر .

- اهتمام الصحف باستخدام الصور الملونة في موضوعاتها لما لها من

قدرة على زيادة التذكر لدى القراء وعدم المبالغة في زيادة أعداد الصور

في الموضوع الواحد التي لم تظهر تقدما ملموسا في زيادة عملية

- التذكر

- اجراء دراسات خاصة بتأثنرات العناوين وأحجامها وألوانها على عملية

التذكر

- الاهتمام بوضع الصورة المصاحبة للمضمون في أماكن بارزة سواء

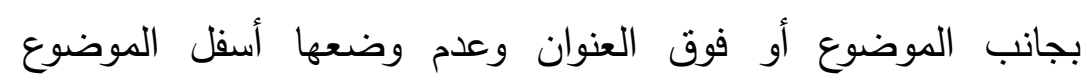

المنشور

- الاهتمام باستخدام الثكل المربع في الصور لما له من قدرة على

جذب الانتباه والمساعدة على التذكر .

- أهمية استخدام الصور الموضوعية لصيقة الصلة بالموضوع المنشور

لما لها من قدرة على زيادة التذكر للمضمون وعدم المبالغة في استخدام الصور الثخصية. 


\section{المراجح}

ا. ميرفت محمد كامل الطرابيشى، تأثير الأشكال الصحفية فى الصحف المصرية على تذكر المعلومات السياسية لدى الثباب الجامعى، المجلة

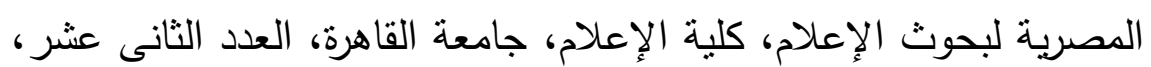

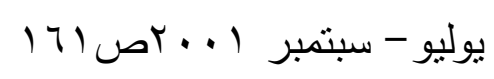

r. سمير محمد محمود، تأثير المعالجة الرقمية لعناصر الثكل المرئى للصحيفة على انتباه وتذكر القراء للأخبار فى إطار نظرية تمثنل المعلومات، دراسة تحليلية وتجربيية لعينة من طلبة الجامعة، رسالة دكتوراه

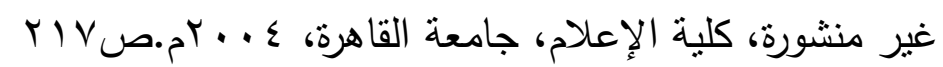
r. المجلة المصرية لبحوث الإعلام ، الاتجاهات العالمية الحديثة لنظريات التأثير فى الراديو والتليفزبون، جامعة القاهرة، كلية الإعلام، العدد السادس اكتوبر -

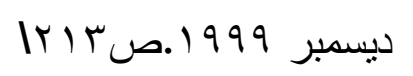

4. James R,Wilson and Stanle Roy Wilson, mass media, mass culture, an introduction, London Mc Grow hill, 4th ed , 1998p17

ه. هشام محمود مصباح، فهم وتذكر الأخبار فى التليفزيون المصرى فى إطار نظرية تمثيل المعلومات، دراسة تحليلية وتجربيية على طلبة الجامعة، رسالة دكتوراه غير منشورة، كلية الإعلام، جامعة القاهرة، .1997

6. Mendelson, Andrew Lawrence, effects of novelty in news photographs on attention and memory, PhD, 


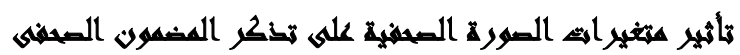

united states , mitsory university, national Abstract, 1997.

$$
\text { 1. . ميرفت محمد كامل الطرابيثى، مرجع سابق محمد محمود،مرجع سابق }
$$

9. هيثم جودة محمد، نأثير الأساليب الاخراجية للصحف الالكترونية على العمليات الادراكية لدى عينة من طلاب الجامعة في إطار نظرية تمثيل المعلومات، رسالة دكتوراه غير منشورة كلية التربية النوعية جامعة

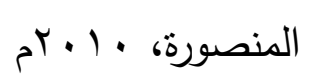

• . . عبير محمد حمدي، تأثنير طرق العرض في ادراك وتذكر المضمون الإخباري. دراسة تجريبية مقارنة بين التليفزيون والوسائط المتعددة عبر الانترنت، رسالة دكتوراه غير منشورة ،كلية الإعلام جامعة القاهرة .116

11. Guo, Jing, the effect of emotion and culture in online news images on memory and attribution assessment of subsequent texet, PhD united states, national abstract , 2013 .

ץ ا ـ سعيد الغريب النجار ، مدخل إلى الإخراج الصحفى، ط ا، الدار المصرية

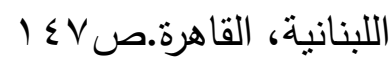

با . محمد نبهان سوبلم، التصوير الإعلامى، طا، القاهرة، دار المعارف، 1910 


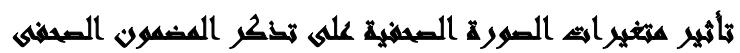

ـ ا. هيثم فتح الله عزيزه، الصورة الصحفية، بغداد، مطبعة الأديب،

$$
\text { 1. } 994
$$

1 . عبد العزيز سعيد الصويعى، الإخراج الصحفى والتصميم بين الأفكار والأخلاق والحواسيب، طا، قبرص، دار الآن للطباعة والنشر، الإهرجة

$$
\text { 1 V0/9 } 991
$$

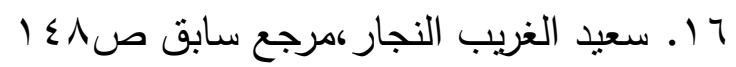
V ا ـ أثرف محمود صالح، شربف درويش اللبان، الإخراج الصحفى الأسس النظرية والتطبيقات العلمية، طا، القاهرة، دار النهضة العربية،

$$
170 \text { (1). I 1 }
$$

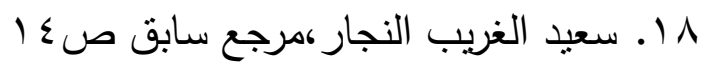

9 1 . فؤاد أحمد فؤاد،العناصر التبوغرافية فى الصحف المصرية (دراسة مقارنة

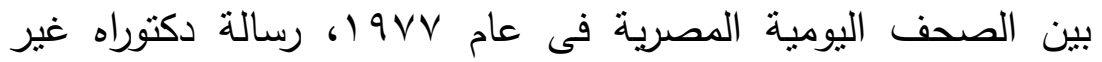

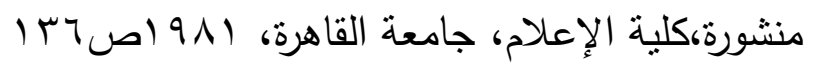
• r. شريف درويش اللبان ، فن الإخراج الصحفى، العربى للنشر والتوزيع،

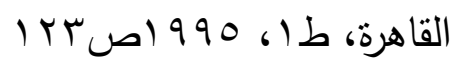
ا Y. شريف درويش اللبان، الألوان فى الصحافة المصرية، القاهرة، العربى

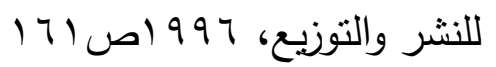

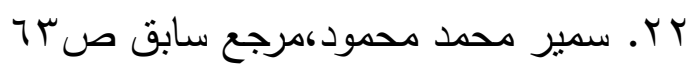

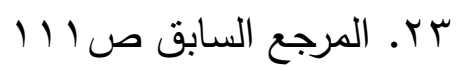
24. Terry L. Childers, Michael J. Houston and Susan E. Hedkler, Measurement of Individual Differences in 


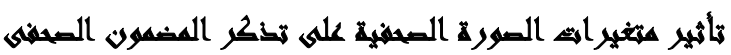

Visual Versus Verbal Information Processing, Journal of Consumer Research, Vol.12,Sep,1985p126

25. Grab and all, Arousing content viewer arousal and memory, Journal of broad casting and electronic media, Vol. 44, No.4m 2000p583

Tr. محمد عبد الحميد، السيد بهنسى، تأثيرات الصورة الصحفية (النظرية

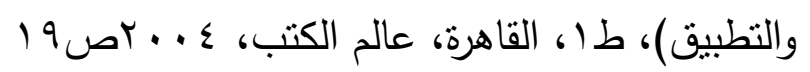

27. Terry L. Childers, Michael J op cit p961

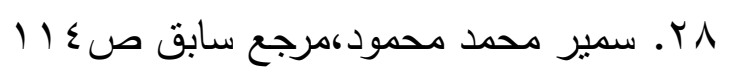

و r. توماس بيري ، الصحافة اليوم ، بيروت ، مؤسسة فرانكلين للطباعة

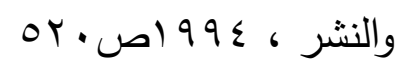

• ץ. راسم محمد الجمال ، الاتصال والاعلام في الوطن العربي كبيروت،مركز

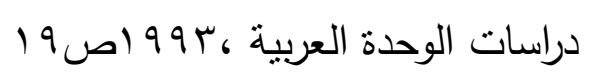

اس. محمد معوض، بركات عبدالعزيز ، الخبر الإذاعي والتليفزبوني ، القاهرة،

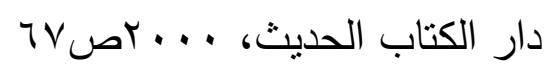

32. Thow . Lieb, editing for clear communication,

London $1996 \mathrm{p} 322$

سب. أسامة عبد الرحيم على، فنون الكتابة الصحفية والعمليات الإدراكية لدى

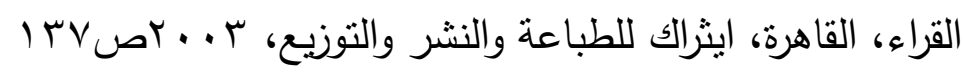

34. Kenneth kobre Photo Journalism, Oxford,Focal Press ,1996p194 


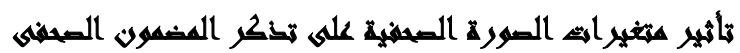

هب. شريف درويش اللبان، الألوان فى الصحافة المصرية، القاهرة، العربى للنشر

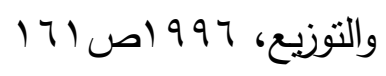

דب. انتصار رسمى دوسى، تصميم وإخراج الصحف والمجلات والإعلانات

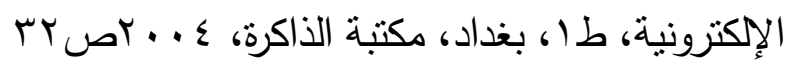

VV. محمود علم الدين، الصورة الفوتوغرافية فى مجالات الإعلام، القاهرة، الهيئة

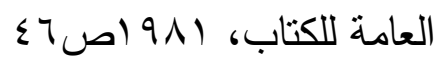

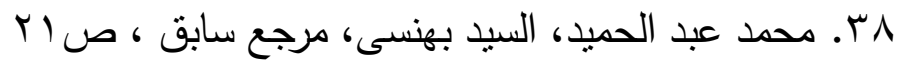

39. Gilberts, K and Schleuder, J. Effects of color and complexity in still photographs on mental effort and memory Journalism quarterly, Vol. 67, No. 4., 1990 p749

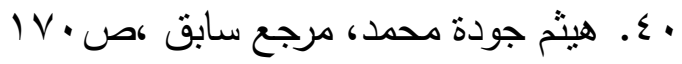

$$
\begin{aligned}
& \text { |ك. عبير محمد حمدي، مرجع سابق، ص || } \\
& \text { r }
\end{aligned}
$$

بـ. أنور محمد الشرقاوي، الادراك في نماذج تكوين وتتاول المعلومات، مجلة

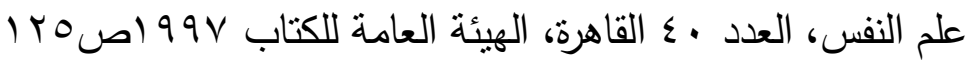
§ء. فرج عبد القادر طه، أصول علم النفس الحديث، القاهرة، عين للدراسات

$$
\text { والبحوث الانسانية والاجتماعية، } 999 \text { (ص • } 199
$$

0ء. سوزان يوسف القلينى، محاضرات فى علم النفس الإعلامى، كلية الآداب،

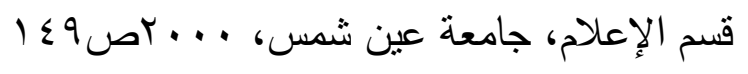

7ـ. همت حسن عبد المجيد، العمليات الادراكية لمعلومات النشرات الصحية 


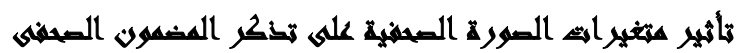

لدى الثباب الجامعي، المجلة المصرية لبحوث الاعلام، العدد هب يوليو -

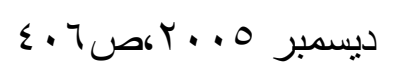

47. Ronald T.kellogg, cognitive psychology, London, sage publication $\mathrm{p} 70$

^ء. طارق فتح الله شبل، فهم وتذكر الأطفال للإعلان التليفزيوني، دراسة تجريبية على عينة من التلاميذ المصريين من سن V- 1 V سنة، رسالة

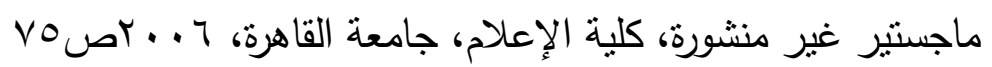
49. Seth Geiger, Revealing the Black Box: Information Processing and media effects, Journal of communication, Vol. 43, No. 4, 1993p44 •.

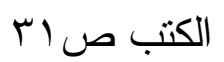

10. مرفت الطرابيشي، عبدالعزيز السيد، نظريات الاتصال، القاهرة، دار

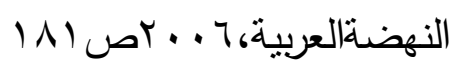

ror. أماني السيد فهي، الاتجاهات الحديثة لنظريات التأثير في الراديو والتليفزيون، المجلة المصرية لبحوث الاعلام، علام القاهرة، العدد أكثوبر

$$
\text { Y) TU } 999
$$

rه. أسماء عبدالحكيم محمد عبداللطيف، مرجع سابق، ص گه. محمد عبدالغني علام، الصفوة المصرية والصحافة دراسة ميدانية في الاستخدامات والاتجاهات، رسالة ماجستير غير منشور، كلية الآداب

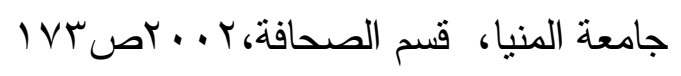




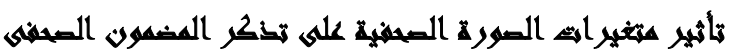

55. Melvin L,Defleur and others, Audience Recall of news story presented by news papers, computer, televion and radio, Journalist quarterly vol 69 no 4 , $1992 p 1018$

07. محمود خليل، الخبر الصحفي، دراسة أسلوبية ،القاهرة العربي للنشر

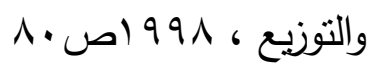

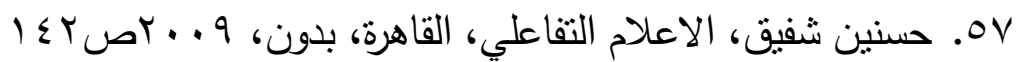

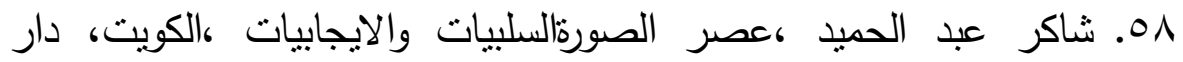

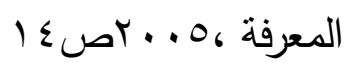

ه9. رباب رأفت محمد الجمال، فنون التحرير الصحفي في الصفحة المسائية،

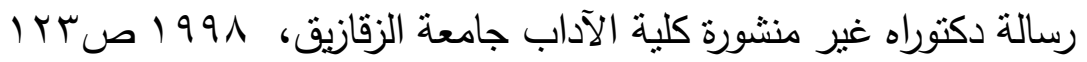

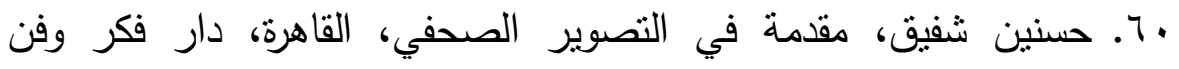

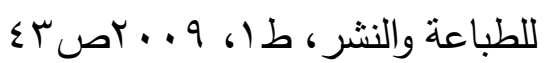

$$
\begin{aligned}
& \text { آT. المرجع السابق صـا }
\end{aligned}
$$

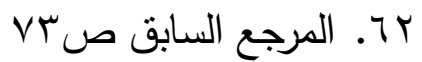

با. أحمد حسين الصاوي، طباعة الصحف وإخراجها، القاهرة، الهيئة العامة

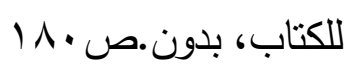

ـ 7. محمد خليل الرفاعي، العوامل المؤثزة على إخراج الصحف السورية، دراسة

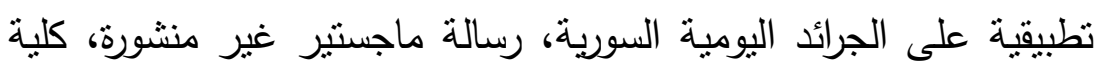

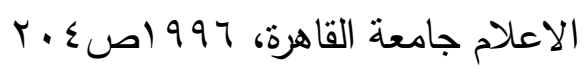

